\title{
HUBUNGAN PENGGUNAAN LAPTOP DAN FUNGSI PENGLIHATAN MAHASISWA ANGKATAN 2011 FAKULTAS KEDOKTERAN UNIVERSITAS SAM RATULANGI MANADO
}

\author{
${ }^{1}$ Sri S. Ningsih, \\ ${ }^{2}$ Fransiska Lintong \\ ${ }^{3}$ Jimmy F. Rumampuk
${ }^{1}$ Kandidat Skripsi Fakultas Kedokteran Universitas Sam Ratulangi Manado
${ }^{2}$ Bagian Fisika Fakultas Kedokteran Universitas Sam Ratulangi Manado \\ Email : sri_suryaningsih23@yahoo.co.id
}

\begin{abstract}
Nowadays, laptop is very trendy because it can be used anywhere. It is very useful in teaching and learning. This study aimed to determine the relation of the use of laptop and visual function. This was a descriptive study using questionnairre and survey. Respondents were students Faculty of Medicine, University of Sam Ratulangi batch 2011. Based on duration, time interval, occurence of complaints, and laptop lighting, the bivariate analysis showed a $P$ value $>0.05$. Conclusion: There was no correlation between the use of laptop and vision function among students of Faculty of Medicine, University of Sam Ratulangi Manado batch 2011.
\end{abstract}

Keywords: laptop, vision

\begin{abstract}
Abstrak: Dewasa ini, laptop sangat diminati karena dapat digunakan dimana saja. Laptop juga berdampak positif bagi proses belajar dan mengajar. Penelitian ini bertujuan untuk mendapatkan hubungan penggunaan laptop dan fungsi penglihatan. Penelitian ini bersifat deskriptif dengan menggunakan survei berupa kuesioner pada mahasiswa angkatan 2011 Fakultas Kedokteran Universitas Sam Ratulangi Manado. Analisis bivariat berdasarkan hubungan antara lama penggunaan laptop, waktu rata-rata pengnaan laptop, jeda, timbulnya keluhan, dan pencahayaan laptop memperlihatkan nilai P $>0,05$. Simpulan: Tidak terdapat hubungan antara penggunaan laptop dan fungsi penglihatan mahasiswa angkatan 2011 Fakultas Kedokteran Universitas Sam Ratulangi Manado.
\end{abstract}

Kata kunci: laptop, penglihatan

Laptop (notebook/powerbook) adalah computer portable (kecil, bisa dibawa kemana-mana) yang terintegrasi pada sebuah casing. Beratnya berkisar dari 1-6 kg tergantung ukuran, bahan dan spesifikasi. Sumber listrik berasal dari baterai atau $\mathrm{A} / \mathrm{C}$ adaptor yang digunakan untuk mengisi ulang baterai dan menyalakan laptop itu sendiri. ${ }^{1}$ Zaman modern ini, laptop sudah menjadi perangkat penting dan tak terpisahkan untuk mendukung aktivitas kita.

Penggunaan laptop dalam bekerja sangat membantu dan memudahkan dalam menyelesaikan pekerjaannya. Penggunaan laptop dewasa ini sudah merambah semua lapisan masyarakat baik komputer desktop maupun laptop. Akhir-akhir ini penggunaan laptop semakin menjadi primadona dibandingkan dengan komputer desktop. Dalam dunia pendidikan, Australia merupakan negara pelopor penggunaan 
laptop dalam lingkungan sekolah. Laptop sangat diminati karena dapat digunakan dimana saja dan juga penggunaan laptop memberikan dampak positif bagi proses belajar dan mengajar. ${ }^{2}$

Medan Elektromagnetik (EM), sebenarnya telah marak dibicarakan dalam beberapa tahun terakhir ini. Banyak pihak yang mengkhawatirkan dampak medan magnetik yang terdapat pada berbagai jenis peralatan elektronik termasuk komputer, terhadap penggunaanya. Mulai dari ketakutan akan gangguan kelahiran yang menyebabkan bayi lahir cacat hingga gangguan yang menyebabkan kanker, pernah menjadi isu seputar dampak medan magnetik. Hingga saat ini belum ada yang tahu pasti mengenai kebenaran dugaan tersebut. Di negara-negara maju seperti Inggris, pemerintahnya telah menganjurkan agar anak-anak di bawah umur mengurangi pemakaian barang-barang yang bermedan elektronik, termasuk komputer bagi anak. Menanggapi kekhawatiran tersebut, Federal Communication Commission (FCC) sebenarnya telah membuat pengukuran khusus yang disebut Specific Absorption Rate (SAR). SAR sendiri berfungsi untuk menyediakan data tingkat radiasi dari tiap tipe elektronik. ${ }^{1,3}$

Saat ini juga banyak mahasiswa yang membawa dan menggunakan laptop untuk membantu mereka dalam proses perkuliahan baik dalam mengerjakan tugas maupun untuk akses internet. Ternyata tak selamanya kemajuan dunia komputer berdampak positif bagi manusia; penggunaan laptop juga menimbulkan dampak negatif karena desain monitor yang menempel pada keyboard akan memberikan masalah bagi para penggunanya. Penggunaan laptop yang meningkat dikalangan mahasiswa serta seringkali digunakan dalam waktu yang lama berisiko untuk menimbulkan keluhan kesehatan.

Terkait dengan penggunaan laptop, keluhan yang paling sering muncul ialah Computer Vision Sindrome (CVS). CVS merupakan kelelahan mata yang dapat mengakibatkan sakit kepala, penglihatan seolah ganda, penglihatan silau terhadap cahaya di waktu malam, dan berbagai masalah penglihatan lainnya. ${ }^{2,4}$

\section{METODE PENELITIAN}

Jenis penelitian ini deskriptif dengan menggunakan survei dan kuesioner. Populasi penelitian ini adalah mahasiswa Universitas Sam Ratulangi. Untuk mendapatkan sampel digunakan tehnik random sampling (sampel random).

Pengujian data dilakukan dengan analisis univariat dan analisis bivariat berdasarkan hubungan antara lama penggunaan laptop, waktu rata-rata pengnaan laptop, jeda, timbulnya keluhan, dan pencahayaan laptop.

\section{HASIL PENELITIAN DAN BAHASAN}

Hasil penelitian menyangkut analisis univariat yang mencakup umur, jenis kelamin, lama menggunakan laptop, waktu rata-rata penggunaan laptop, jeda penggunaan laptop, keluhan yang timbul, kontras laptop, jenis gangguan pada mata. Analisis bivariat mencakup hubungan lama penggunaan laptop dengan gangguan pada mata; waktu rata-rata penggunaan laptop dengan gangguan pada mata; jeda penggunaan laptop dengan gangguan pada mata; keluhan yang timbul dengan gangguan pada mata; serta kontras laptop dengan gangguan pada mata

\section{Analisis Univariat}

Tabel 1 memperlihatkan karakteristik umur responden dimana sebagian besar berumur 19 tahun (56,7\%) dan yang paling sedikit umur 20 tahun (10\%).

Tabel 1. Karakteristik Umur Responden

\begin{tabular}{ccc}
\hline Umur & $\mathrm{N}$ & $\%$ \\
\hline 18 tahun & 10 & 33,3 \\
19 tahun & 17 & 56,7 \\
20 tahun & 3 & 10,0 \\
Total & 30 & 100 \\
\hline
\end{tabular}


Tabel 2 menjelaskan karakteristik jenis kelamin responden dimana sebagian besar ialah perempuan $(76,7 \%)$ dan yang paling sedikit laki-laki (23,3\%).

Tabel 2. Karakteristik Jenis Kelamin Responden

\begin{tabular}{ccc}
\hline Jenis Kelamin & $\mathrm{n}$ & $\%$ \\
\hline Laki-laki & 7 & 23,3 \\
Perempuan & 23 & 76,7 \\
Total & 30 & 100 \\
\hline
\end{tabular}

Tabel 3 menjelaskan tentang lama penggunaan laptop dimana sebagian besar telah menggunakan laptop selama $>2$ tahun $(93,3 \%)$.

Tabel 3. Karakteristik menurut Lama Penggunaan Laptop

\begin{tabular}{ccc}
\hline $\begin{array}{c}\text { Lama } \\
\text { Penggunaan } \\
\text { Laptop }\end{array}$ & $\mathrm{n}$ & $\%$ \\
\hline$<2$ tahun & 2 & 6,7 \\
$>2$ tahun & 28 & 93,3 \\
Total & 30 & 100 \\
\hline
\end{tabular}

Tabel 4 menjelaskan tentang karakteristik waktu rata-rata penggunaan laptop dimana sebagian besar penggunaan laptop selama 2-3 jam (40\%) dan yang paling sedikit ialah $<1$ jam $(3,3 \%)$.

Tabel 4. Karakteristik Waktu Rata-rata Penggunaan Laptop

\begin{tabular}{ccc}
\hline $\begin{array}{c}\text { Waktu Rata-rata } \\
\text { Penggunaan Laptop }\end{array}$ & $\mathrm{n}$ & $\%$ \\
\hline$<1$ jam & 1 & 3,3 \\
$1-2$ jam & 7 & 23,3 \\
$2-3$ jam & 12 & 40 \\
$>4$ jam & 10 & 33,3 \\
Total & 30 & 100 \\
\hline
\end{tabular}

Tabel 5 menjelaskan tentang jeda penggunaan laptop responden dimana sebagian besar ada jeda (73,3\%) sedangkan yang tanpa jeda $26,7 \%$.
Tabel 5. Karakteristik Jeda Penggunaan Laptop Responden

\begin{tabular}{ccc}
\hline $\begin{array}{c}\text { Jeda Penggunaan } \\
\text { Laptop }\end{array}$ & $\mathrm{n}$ & $\%$ \\
\hline Ya & 22 & 73,3 \\
Tidak & 8 & 26,7 \\
Total & 30 & 100 \\
\hline
\end{tabular}

Tabel 6 menjelaskan tentang waktu timbulnya keluhan-keluhan dimana sebagian besar keluhan timbul pada penggunaan setelah 1-2 jam (36,7\%) dan yang paling sedikit ialah $<1$ jam (3,3\%).

Tabel 6. Karakteristik Waktu timbulnya Keluhan Responden

\begin{tabular}{ccc}
\hline Waktu & $\mathrm{n}$ & $\%$ \\
Timbulnya Keluhan & & \\
\hline$<1$ jam & 1 & 3,3 \\
$1-2$ jam & 11 & 36,7 \\
$2-3$ jam & 9 & 30 \\
$>4$ jam & 9 & 30 \\
Total & 30 & 100 \\
\hline
\end{tabular}

Keluhan yang timbul pada mata dapat berupa mata gatal, perih, tegang, silau, kabur, dan sakit kepala

Tabel 7 menjelaskan tentang keluhan mata gatal yang timbul dimana sebagian besar tidak mengeluh gatal (70\%).

Tabel 7. Karakteristik Keluhan Mata Gatal Responden

\begin{tabular}{ccc}
\hline $\begin{array}{c}\text { Keluhan Mata } \\
\text { Gatal }\end{array}$ & $\mathrm{N}$ & $\%$ \\
\hline Ya & 9 & 30 \\
Tidak & 21 & 70 \\
Total & 30 & 100 \\
\hline
\end{tabular}

Tabel 8 menjelaskan tentang keluhan mata perih yang timbul dimana sebagian besar mengeluh mata perih (63,3\%).

Tabel 9 menjelaskan tentang keluhan mata berair yang timbul dimana sebagian besar mengeluh mata berair (80\%). 
Ningsih, Lintong, Rumampuk: Hubungan penggunaan laptop...

Tabel 8. Karakteristik Keluhan Mata Perih Responden

\begin{tabular}{ccc}
\hline $\begin{array}{c}\text { Keluhan } \\
\text { Mata Perih }\end{array}$ & $\mathrm{n}$ & $\%$ \\
\hline Ya & 19 & 63,3 \\
Tidak & 11 & 36,7 \\
Total & 30 & 100 \\
\hline
\end{tabular}

Tabel 9. Karakteristik Keluhan Mata Kering Responden

\begin{tabular}{ccc}
\hline $\begin{array}{c}\text { Keluhan } \\
\text { Mata Tegang }\end{array}$ & $\mathrm{n}$ & $\%$ \\
\hline Ya & 16 & 53,3 \\
Tidak & 14 & 46,7 \\
Total & 30 & 100 \\
\hline
\end{tabular}

Tabel 10 menjelaskan tentang keluhan mata silau yang timbul dimana sebagian besar mengeluh mata silau (66,7\%).

Tabel 10. Karakteristik Keluhan Mata Silau Responden

\begin{tabular}{ccc}
\hline $\begin{array}{c}\text { Keluhan } \\
\text { Mata Silau }\end{array}$ & $\mathrm{n}$ & $\%$ \\
\hline Ya & 20 & 66,7 \\
Tidak & 10 & 33,3 \\
Total & 30 & 100 \\
\hline
\end{tabular}

Tabel 11 menjelaskan tentang keluhan penglihatan kabur yang timbul dimana sebagian besar mengeluh mata kabur sebanyak 23 responden (76,7\%).

Tabel 11. Karakteristik Keluhan Penglihatan Kabur Responden

\begin{tabular}{ccc}
\hline $\begin{array}{c}\text { Keluhan } \\
\text { Mata Kabur }\end{array}$ & $\mathrm{n}$ & $\%$ \\
\hline Ya & 23 & 76,7 \\
Tidak & 7 & 23,3 \\
Total & 30 & 100 \\
\hline
\end{tabular}

Tabel 12 menjelaskan tentang keluhan sakit kepala yang timbul dimana sebagian responden mengeluh sakit kepala (43,3\%).

Tabel 13 menjelaskan tentang karakteristik pencahayaan laptop dimana sebagian besar ada pencahayaan laptop (73,3\%).
Tabel 12. Karakteristik Keluhan Sakit Kepala Responden

\begin{tabular}{ccc}
\hline $\begin{array}{c}\text { Keluhan } \\
\text { Sakit Kepala }\end{array}$ & $\mathrm{n}$ & $\%$ \\
\hline Ya & 17 & 43,3 \\
Tidak & 13 & 56,7 \\
Total & 30 & 100 \\
\hline
\end{tabular}

Tabel 13. Karakteristik pencahayaan Laptop

\begin{tabular}{ccc}
\hline $\begin{array}{c}\text { Pencahayaan } \\
\text { Laptop }\end{array}$ & $\mathrm{n}$ & $\%$ \\
\hline Ya & 22 & 73,3 \\
Tidak & 8 & 26,7 \\
\hline Total & 30 & 100 \\
\hline
\end{tabular}

Tabel 14 menjelaskan tentang karakteristik gangguan mata responden dimana sebagian besar tidak ada gangguan (normal) (70\%).

Tabel 14. Karakteristik Gangguan Mata Responden

\begin{tabular}{ccc}
\hline Gangguan & $\mathrm{n}$ & $\%$ \\
\hline Normal & 21 & 70 \\
Gangguan & 9 & 30 \\
Total & 30 & 100 \\
\hline
\end{tabular}

Tabel 15 menjelaskan tentang karakteristik hasil pemeriksaan mata kiri yaitu responden dengan visus 6/6 56,7\%, visus $6 / 7,5$ 26,7\%, dan visus 6/9 16,7\%.

Tabel 15. Karakteristik Hasil Pemeriksaan Mata Kiri

\begin{tabular}{ccc}
\hline Visus & $\mathrm{n}$ & $\%$ \\
\hline $6 / 6$ & 17 & 56,7 \\
$6 / 7,5$ & 8 & 26,7 \\
$6 / 9$ & 5 & 16,7 \\
Total & 30 & 100,0 \\
\hline
\end{tabular}

Tabel 16 menjelaskan tentang karakteristik hasil pemeriksaan mata kanan dimana responden dengan visus $6 / 653,3 \%$, visus $6 / 7,536,7 \%$, dan visus $6 / 9$ 10,0\%. 
Tabel 16. Karateristik Hasil Pemeriksaan Mata Kanan

\begin{tabular}{ccc}
\hline Visus & $\mathrm{n}$ & $\%$ \\
\hline $6 / 6$ & 16 & 53,3 \\
$6 / 7,5$ & 11 & 36,7 \\
$6 / 9$ & 3 & 10,0 \\
Total & 30 & 100,0 \\
\hline
\end{tabular}

Analisis Bivariat

Hubungan Lama Penggunaan Laptop dengan Gangguan pada Mata

Berdasarkan analisis data pada Tabel 17 dapat dilihat bahwa sebagian besar responden $(63,3 \%)$ dengan penggunaan laptop $>2$ tahun tidak mempunyai gangguan mata (normal). Analisis data untuk mengetahui hubungan lama penggunaan laptop dengan gangguan pada mata ialah uji Fisher Exact Test dengan tingkat kepercayaan 95\% dan tingkat kesalahan 5\% $(\alpha=0,05)$. Hasil analisis data diperoleh nilai $p=0,483>0,05$, yang menunjukkan tidak terdapat hubungan antara lama penggunaan laptop dengan gangguan pada mata.

\section{Hubungan Waktu Rata-rata Penggunaan Laptop dengan Gangguan pada Mata}

Berdasarkan analisis data pada Tabel 18 dapat dilihat bahwa responden dengan waktu rata-rata penggunaan laptop 2-3 jam yang tidak mempunyai gangguan mata (normal) berjumlah 8 responden $(26,7 \%)$ dan yang mengalami gangguan sebanyak 4 responden (13,3\%). Analisis data untuk mengetahui hubungan lama penggunaan laptop dengan gangguan pada mata ialah uji Chi-Square dengan tingkat kepercayaan 95\% dan tingkat kesalahan 5\% $(\alpha=0,05)$. Hasil analisis data diperoleh nilai $p=0,118$ $>0,05$, yang menunjukkan bahwa tidak terdapat hubungan antara rata-rata waktu penggunaan laptop dengan gangguan pada mata.

\section{Hubungan Jeda Penggunaan Laptop dengan Gangguan pada Mata}

Berdasarkan analisis data pada tabel 19 dapat dilihat bahwa sebagian besar responden memiliki jeda penggunaan laptop dan tidak mempunyai gangguan mata (normal) sebanyak 14 responden (46,7\%) dan yang mengalami gangguan sebanyak 8 responden (26,7\%). Analisis data yang digunakan untuk mengetahui hubungan lama penggunaan laptop dengan gangguan pada mata oalah uji Fisher Exact Test dengan tingkat kepercayaan 95\% dan tingkat kesalahan 5\% $(\alpha=0,05)$. Hasil analisis data diperoleh nilai $p=0,214>$ 0,05, yang menunjukkan tidak terdapat hubungan antara jeda penggunaan laptop dengan gangguan pada mata.

\section{Hubungan Timbulnya Keluhan dengan Gangguan pada Mata}

Berdasarkan analisis data pada tabel 20 dapat dilihat bahwa $3,3 \%$ responden mengalami keluhan pada mata dengan penggunaan laptop $>4$ jam sedangkan yang tidak mempunyai gangguan mata (normal) $26,7 \%$ dan yang mengalami gangguan sebanyak 6 responden (20\%) dengan keluhan 1-2 jam. Analisis data yang digunakan untuk mengetahui hubungan lama penggunaan laptop dengan gangguan pada mata ialah uji Chi Square menggunakan tingkat kepercayaan 95\% dan tingkat kesalahan 5\% $(\alpha=0,05)$. Hasil analisis data diperoleh nilai $p=0,146>$ 0,05 , yang menunjukkan bahwa tidak terdapat hubungan antara lama timbulnya keluhan pada mata dengan gangguan pada mata.

\section{Hubungan Pencahayaan Laptop dengan Gangguan pada Mata}

Berdasarkan analisis data pada tabel 21 dapat dilihat bahwa sebagian besar responden (53,3\%) dengan adanya pencahayaan laptop dan tidak mempunyai gangguan mata (normal) sedangkan yang mengalami gangguan sebesar 20\%. Analisis data yang digunakan untuk mengetahui hubungan lama penggunaan laptop dengan gangguan pada mata ialah uji Fisher Exact Test dengan tingkat 
Ningsih, Lintong, Rumampuk: Hubungan penggunaan laptop...

kepercayaan 95\% dan tingkat kesalahan 5\% bahwa tidak terdapat hubungan antara $(\alpha=0,05)$. Hasil analisis data diperoleh kontras laptop dengan gangguan pada mata. nilai $p=0,453>0,05$, yang menunjukkan

Tabel 17. Hasil Tabulasi Silang Lama Penggunaan Laptop dengan Gangguan pada Mata

\begin{tabular}{ccccccccc}
\hline & \multicolumn{7}{c}{ Kriteria Gangguan } & \multirow{2}{*}{$P$} \\
\cline { 2 - 8 } & Normal & $\%$ & Gangguan & $\%$ & Jumlah & $\%$ & \\
\hline $\begin{array}{c}\text { Lama } \\
\text { penggunaan } \\
\text { Laptop }\end{array}$ & $>2$ thn & 2 & 6,7 & 0 & 0 & 2 & 6,7 & \\
\cline { 2 - 8 } & $>2$ thn & 19 & 63,3 & 9 & 30 & 28 & 93,3 & 0,483 \\
\hline \multicolumn{2}{c}{ Total } & 21 & & 9 & 49,5 & 30 & 100 & \\
\hline
\end{tabular}

Tabel 18. Hasil Waktu rata-rata LamaPenggunaan Laptop dengan Gangguan pada Mata

\begin{tabular}{|c|c|c|c|c|c|c|c|c|}
\hline & & \multicolumn{4}{|c|}{ KriteriaGangguan } & & & \multirow{2}{*}{$P$} \\
\hline & & Normal & $\%$ & Gangguan & $\%$ & Jumlah & $\%$ & \\
\hline \multirow{4}{*}{$\begin{array}{l}\text { Waktu Rata- } \\
\text { rata } \\
\text { Penggunaan } \\
\text { Laptop }\end{array}$} & $<1$ jam & 0 & 0 & 1 & 3,3 & 1 & 3,3 & \multirow{5}{*}{0,483} \\
\hline & $\begin{array}{l}1-2 \\
\text { jam }\end{array}$ & 7 & 23,3 & 0 & 0 & 7 & 23,3 & \\
\hline & $\begin{array}{l}2-3 \\
\text { jam }\end{array}$ & 8 & 26,7 & 4 & 13,3 & 12 & 40 & \\
\hline & $>4$ jam & 6 & 20 & 4 & 13,3 & 10 & 33,3 & \\
\hline \multicolumn{2}{|c|}{ Total } & 21 & 70 & 9 & 30 & 30 & 100 & \\
\hline
\end{tabular}

Tabel 19. Hasil Tabulasi Silang Jeda Penggunaan Laptop dengan Gangguan pada Mata

\begin{tabular}{|c|c|c|c|c|c|c|c|c|}
\hline & & \multicolumn{4}{|c|}{ KriteriaGangguan } & \multirow[b]{2}{*}{ Jumlah } & \multirow[b]{2}{*}{$\%$} & \multirow[b]{2}{*}{$p$} \\
\hline & & Normal & $\%$ & Gangguan & $\%$ & & & \\
\hline \multirow{2}{*}{$\begin{array}{c}\text { Jeda penggunaan } \\
\text { laptop } \\
\end{array}$} & $\mathrm{Ya}$ & 14 & 46,7 & 8 & 26,7 & 22 & 73,3 & \multirow{2}{*}{0,214} \\
\hline & tidak & 7 & 23,3 & 1 & 3,3 & 8 & 26,7 & \\
\hline Total & & 21 & 70 & 9 & 49,5 & 30 & 100 & \\
\hline
\end{tabular}

Tabel 20. Hasil Tabulasi Silang Timbulnya Keluhan dengan Gangguan pada Mata

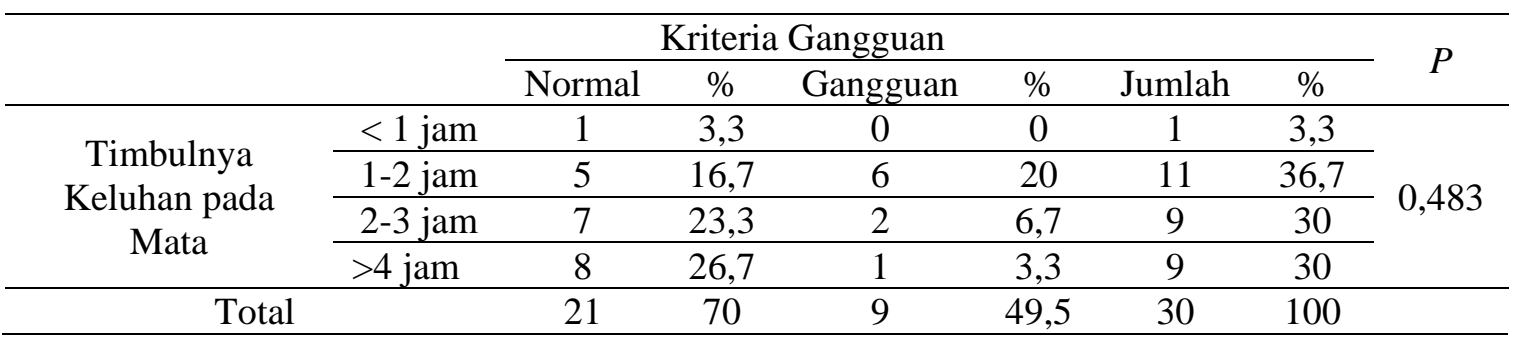

Tabel 21. Hasil Tabulasi Silang Timbulnya Keluhan dengan Gangguan pada Mata

\begin{tabular}{|c|c|c|c|c|c|c|c|c|}
\hline & & \multicolumn{4}{|c|}{ KriteriaGangguan } & & & \multirow[b]{2}{*}{$p$} \\
\hline & & Normal & $\%$ & Gangguan & $\%$ & Jumlah & $\%$ & \\
\hline \multirow{2}{*}{$\begin{array}{l}\text { Kontras } \\
\text { Laptop }\end{array}$} & $\mathrm{Ya}$ & 16 & 53,3 & 6 & 20 & 22 & 73,3 & \multirow{2}{*}{0,453} \\
\hline & Tidak & 5 & 16,7 & 3 & 10 & 8 & 26,7 & \\
\hline \multicolumn{2}{|c|}{ Total } & 21 & 70 & 9 & 30 & 30 & 100 & \\
\hline
\end{tabular}




\section{SIMPULAN}

Berdasarkan hasil analisis hubungan antara lama penggunaan laptop, waktu ratarata pengnaan laptop, jeda, timbulnya keluhan, dan pencahayaan laptop disimpulkan bahwa tidak terdapat hubungan antara penggunaan laptop dan fungsi penglihatan mahasiswa angkatan 2011 Fakultas Kedokteran Universitas Sam Ratulangi Manado.

\section{DAFTAR PUSTAKA}

1. Indra S. Dampak penggunaan laptop yang mengakibatkan gangguan kesehatan (Abstrak). Fak. Informatika Politeknik Negeri Sriwijaya.
Available from: http://gilib.unsri.ac.id. 30 Mei 2009.

2. Aryanti. Dampak negatif penggunaan komputer bagi kesehatan [Skripsi]. 2010 Sept 20. Available from: http: //uppm.fkm.unes.ac.id/uploads/files/u _2/abstrak4.doc.

3. Hendra, Octaviani DF. Keluhan kesehatan akibat penggunaan laptop pada mahasiswa FKMUI. Available from: http://staf.ui.ac.id/internal/132255817 /publikasi/keluhankesehatanakibatpen ggunaanlaptoppadamahasiswa.fkm.pd f.2009.

4. Agta Z. 2010. Menjaga kesehatan mata saat di depan komputer. Available from: http://www.kompas.com. 